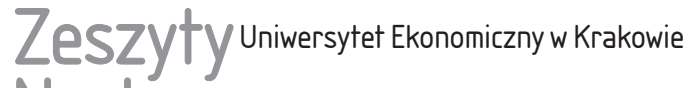 Naukowe
}

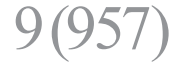

ISSN 1898-6447

Zesz. Nauk. UEK, 2016; 9(957): 89-100 DOI: 10.15678/ZNUEK.2016.0957.0906

Iwona Foryś

Radosław Gaca

\section{Teoretyczne i praktyczne aspekty opisu cech jakościowych nieruchomości w modelach regresji wielorakiej wyceny wartości mieszkań*}

\section{Streszczenie}

Dynamiczny rozwój teorii wyceny wartości rynkowej nieruchomości związany jest w Polsce z transformacją ustrojową. Wraz ze wzrostem liczby zawieranych transakcji na tym rynku oraz coraz liczniejszymi obszarami aktywności gospodarczej wymagającej określania wartości nieruchomości pojawiają się próby wprowadzania do praktyki modeli regresji wielorakiej. Niedoskonałości samego modelu regresji, a także cechy nieruchomości jako realnych obiektów opisywanych w modelach są przyczyną sprzecznych i niezasadnych wniosków z nich płynących. Jedną z przyczyn niedoskonałości funkcjonalnej modeli regresji jest sposób wprowadzania do nich zmiennych jakościowych, które w wielu przypadkach są najistotniejszymi cechami opisującymi nieruchomości.

Zgodnie z podstawowymi zasadami określającymi możliwe działania na liczbach ze względu na rodzaj skal pomiarowych zmienne jakościowe mierzone na skali nominalnej

Iwona Foryś, Uniwersytet Szczeciński, Instytut Ekonometrii i Statystyki, Katedra Badań Operacyjnych i Zastosowań Matematyki w Ekonomii, 71-101 Szczecin, ul. Mickiewicza 64, e-mail: forys@wneiz.pl

Radosław Gaca, e-mail: rgaca@poczta.onet.pl

* W materiałach konferencyjnych [Foryś i Gaca 2016b] prezentowano wyniki wstępne badań, które w niniejszym artykule zostały dodatkowo uzupełnione o kolejny badany obiekt. 
i porządkowej mogą być wprowadzane do modeli regresji w postaci zmiennych sztucznych (dummy variables). W niniejszym artykule przedstawiona został propozycja alternatywnej metody wprowadzania zmiennych jakościowych do modeli regresji wielorakiej opisujących rynki nieruchomości, poprzez zastosowanie do ich pomiaru skali Osgooda.

W pracy zaprezentowane zostały nie tylko podstawy teoretyczne proponowanego modelu, ale również wyniki jego zastosowania w zestawieniu z klasyczną metodą wprowadzania zmiennych jakościowych. Rozważania teoretyczne zostały poparte badaniem empirycznym na rynku mieszkaniowym Szczecina, Bydgoszczy oraz Świecia (województwo zachodniopomorskie).

Słowa kluczowe: wycena nieruchomości, zmienne jakościowe, skala Osgooda, skala semantyczna, regresja wieloraka.

Klasyfikacja JEL: C50, R30.

\section{Wprowadzenie}

Rozwój rynku nieruchomości w Polsce po okresie burzliwych przemian społeczno-gospodarczych wynikających z transformacji ustrojowej jest ściśle związany z rozwojem teorii wyceny wartości rynkowej nieruchomości. Dostosowanie metodologii wyceny do coraz liczniejszych obszarów aktywności gospodarczej wymagających określania wartości nieruchomości skutkuje próbami adoptowania do tych celów metod ilościowych.

Wśród wspomnianych metod popularne są zwłaszcza modele regresji wielorakiej, jednak niedoskonałości samego modelu regresji, a także cechy nieruchomości bywają przyczyną sprzecznych i niezasadnych wniosków z nich płynących, zwłaszcza że najistotniejsze - biorąc pod uwagę wartość - cechy nieruchomości jako realnych obiektów opisywanych w modelach [Social Entrepreneurship... 2014, Green 1991, Preachera i in. 2013] są zazwyczaj mierzone na skalach słabych.

Celem przeprowadzonych badań jest sprawdzenie możliwości zastosowania alternatywnej w stosunku do powszechnie stosowanej metody wprowadzania zmiennych jakościowych [Bennett i Elman 2006] do modeli regresji wielorakiej opisujących rynki nieruchomości, opartej na zmiennych sztucznych (dummy variables), poprzez zastosowanie do ich pomiaru skali Osgooda [Foryś i Gaca 2016b].

Problematyka kwantyfikacji stanów cech nieruchomości była dotychczas przedmiotem licznych opracowań [Foryś 2011, Hozer 2001, Bełej i Źróbek 2000]. W przywołanych publikacjach nie podjęto jednak szerszej dyskusji na temat zasad wprowadzania zmiennych jakościowych do modeli, w szczególności biorąc pod uwagę dopuszczalność działań na liczbach ze względu na skalę pomiaru.

Zgodnie z koncepcją zaprezentowaną przez S.S. Stevensa [1946] wyróżnić można cztery skale: nominalną, porządkową, przedziałową i ilorazową. Zgodnie z zasadami pomiaru z określonym typem skali wiążą się dopuszczalne grupy 
przekształceń, jak również dopuszczalne działania arytmetyczne [Walesiak 1996, Knapp 1990]. Z założeń metody kwantyfikacji zaproponowanej przez Stevensa wynika, że dane liczbowe wyrażone w skalach niskiego rzędu (nominalnej i porządkowej) nie posiadają typowej dla liczb naturalnych interpretacji. Dla danych wyrażonych na wymienionych skalach oznaczenia liczbowe mają charakter kodów różnicujących i pozycjonujących. Wskazane liczby w klasycznym ujęciu nie opisują jednak ani odległości (interwału), ani stosunku (ilorazu) poszczególnych zmiennych.

Zgodnie z jedną z podstawowych reguł pomiaru rezultaty pomiaru opisane w skali mocniejszej mogą być transformowane na liczby należące wyłącznie do skali słabszej. Odwrotna transformacja danych polegająca na ich wzmacnianiu nie jest możliwa. Wynika to z prostego faktu związanego z ilością niesionej przez dany pomiar informacji [Walesiak 1996, Wiśniewski 1986, Walesiak i Dudek 2007]. Istnieją, co prawda, metody pozwalające na transformację danych mierzonych na skali porządkowej na skalę interwałową, jednak transformacja taka nie powoduje przyrostu informacji zawartej w przetransformowanych danych [Walesiak 2014].

Zaproponowana przez autorów niniejszego artykułu metoda wyrażania stanów (poziomów) cech jakościowych poprzez zastosowanie skali opartej na dyferencjale semantycznym [Foryś i Gaca 2016a] zbliża uzyskane za jej pomocą wyniki do pomiaru wykonanego na skali co najmniej interwałowej [Johnson 2010].

\section{Metoda badań}

W modelach regresji w celu przeprowadzenia falsyfikacji hipotezy dotyczącej poprawności alternatywnej metody wprowadzania zmiennych jakościowych wyrażonych za pomocą dyferencjału semantycznego, a ponadto $\mathrm{w}$ celu falsyfikacji hipotezy dotyczącej interwałowego i równomiernego rozkładu zmienności poszczególnych stanów cech jakościowych, dokonano porównania wyników estymacji parametrów modelu regresji liniowej z wykorzystaniem dwóch metod modelowania zmiennych jakościowych, tj. metody, w przypadku której zmienne jakościowe skwantyfikowane za pomocą skali Osgooda wprowadzono do modelu bezpośrednio na podstawie ich wartości, oraz metody, w przypadku której opisane wyżej zmienne przekształcono na zmienne sztuczne [Foryś i Gaca 2016b].

Obliczeń dokonano, wykorzystując model liniowej regresji wielorakiej w postaci:

$$
Y=\alpha_{0}+\alpha_{1} X_{1}+\alpha_{2} X_{2} \ldots \alpha_{m} X_{m}+\varepsilon,
$$


gdzie:

$Y$ - zmienna objaśniana (ceny nieruchomości),

$X_{i}$ - zmienne objaśniające (stany cech); $i=1,2, \ldots, m$,

$\varepsilon-$ składnik losowy.

Jako podstawę estymacji parametrów modelu przyjęto macierz A cech nieruchomości dla analizowanego zbioru nieruchomości podobnych:

$$
\mathbf{A}=\left[\begin{array}{ccc}
x_{11} & \ldots & x_{1 m} \\
x_{21} & \ldots & x_{2 m} \\
\ldots & \ldots & \ldots \\
x_{n 1} & \ldots & x_{n m}
\end{array}\right] .
$$

Informacje zawarte w macierzy A stanowią podstawę do określenia wartości nieruchomości zgodnie z podejściem porównawczym, prowadzącym do szacowania wartości rynkowej nieruchomości. Cechy rynkowe obejmujące zmienne jakościowe opisane w macierzy A skwantyfikowane zostały z wykorzystaniem skali Osgooda [Osgood i in. 1957, Foryś i Gaca 2016a].

Konstrukcja skali oparta jest na ocenie przez respondenta poziomu nasilenia zjawiska bądź stanu obiektu, poprzez określenie w formie semantycznej. Wówczas pomiar znaczenia konotacyjnego sprowadza się do wskazania miejsca zajmowanego w przestrzeni semantycznej przez dane pojęcie czy nazwę. $Z$ prowadzonych przez Osgooda analiz wynikało, że do zasadniczych wymiarów określonej przestrzeni semantycznej należą: wartościowanie, siła i aktywność. Własności opisanych skal pozwalają na potraktowanie uzyskanych przy ich zastosowaniu danych jako danych o charakterze semiinterwałowym. Opisany charakter skal wynika z samej ich konstrukcji opartej na ocenie „położenia” postawy lub opinii względem stanu przeciętnego (neutralnego) i stanów skrajnych w danej grupie [Osgood i in. 1957, Foryś i Gaca 2016b].

W przypadku stosowania oceny cech jakościowych za pomocą dyferencjału semantycznego niezwykle ważne jest prawidłowe zdefiniowanie zakresów ocen maksymalnych i minimalnych. Biorąc pod uwagę powyższe, skalą o najlepszych właściwościach byłaby skala posiadającą zakresy skrajnych ocen odpowiadających uniwersalnemu znaczeniu wartościującemu właściwemu dla danej społeczności. Uwzględniając jednak konieczność budowy modelu wyceny nieruchomości zgodnie z podejściem porównawczym na podstawie nieruchomości podobnych, należy zauważyć, że w większości przypadków poziom zróżnicowania stanów określonych cech różnicujących nieruchomości w badanej grupie będzie mniejszy i stanowić będzie jedynie fragment całkowitej rozpiętości ocen. W przypadku oceny stanów cech nieruchomości z wykorzystaniem koncepcji Osgooda należy dla każdej analizowanej grupy dokonać odrębnej oceny i skalowania odpowiadającego zdiagnozowanym stanom skrajnym i stanowi przeciętnemu. Również zakres 
gradacji skali musi być w każdym przypadku dostosowany do zaobserwowanego zróżnicowania cech.

W celu falsyfikacji hipotezy o co najmniej interwałowym charakterze zmiennych opisujących stany nieruchomości kwantyfikowanych za pomocą dyferencjału semantycznego przeprowadzono porównanie wyników estymacji dla dwóch opisanych modeli regresji [Foryś i Gaca 2016a, 2016b].

Obliczeń dla modelu ze zmiennymi sztucznymi dokonano na podstawie modelu liniowej regresji wielorakiej w postaci:

$$
Y=\alpha_{0}+\alpha_{12} D_{12}+\alpha_{13} D_{13}+\alpha_{22} D_{22} \ldots+\alpha_{m k} D_{m k}+\varepsilon,
$$

gdzie:

$Y$ - zmienna objaśniana (ceny nieruchomości),

$D_{i j}$ - zmienne objaśniające (stany cech) przekształcone na zmienne sztuczne; $i=1,2, \ldots, m ; j=1,2, \ldots, k$,

$\varepsilon-$ składnik losowy.

Przekształcenia zmiennych jakościowych skwantyfikowanych z wykorzystaniem skali Osgooda w zmienne sztuczne dokonano zgodnie z podanymi poniżej wzorami [Hardy 1993]:

- dla zmiennych o dwóch stanach:

$$
D_{1}=\left\{\begin{array}{l}
1 \text { dla oceny } 2 \\
0 \text { dla oceny } 1,
\end{array}\right.
$$

- dla zmiennych o trzech stanach:

$$
\begin{aligned}
& D_{1}=\left\{\begin{array}{l}
1 \text { dla oceny } 2 \\
0 \text { dla ocen } 1 \mathrm{i} 3,
\end{array}\right. \\
& D_{1}=\left\{\begin{array}{l}
1 \text { dla oceny } 3 \\
0 \text { dla ocen } 1 \text { i } 2 .
\end{array}\right.
\end{aligned}
$$

Na podstawie dokonanych przekształceń otrzymano macierz $\mathbf{A}^{\prime}$ zmiennych sztucznych w postaci:

$$
\mathbf{A}^{\prime}=\left[\begin{array}{cccc}
d_{1_{12}} & d_{1_{13}} & \ldots & d_{1_{m k}} \\
d_{212} & d_{2_{13}} & \ldots & d_{2_{m k}} \\
\ldots & \ldots & \ldots & \ldots \\
d_{n_{12}} & d_{n_{13}} & \ldots & d_{n_{m k}}
\end{array}\right] .
$$

Wyboru kodowania zero-jedynkowego (dummy coding) dokonano ze względu na chęć uzyskania wartości współczynników dla poszczególnych wektorów zmiennych sztucznych odpowiadających poszczególnym stanom (poziomom) jakościowych zmiennych objaśniających, dla których punkt odniesienia stanowi w każdym przypadku pierwszy (najniższy) stan (poziom) cechy. Powyższy sposób kodowania pozwala na określenie proporcji pomiędzy obliczonymi wartościami 
współczynników dla poszczególnych poziomów cech jakościowych i ich porównanie w stosunku do kwantyfikacji dokonanej z wykorzystaniem skali dyferencjału semantycznego.

\section{Badania empiryczne}

Weryfikacji założeń dokonano na podstawie trzech zbiorów nieruchomości podobnych obejmujących prawa do lokali mieszkalnych położonych na terenie Bydgoszczy, Szczecina oraz mniejszego ośrodka miejskiego Świecia. W celu uzyskania zbiorów obejmujących zmienność w obszarze wyłącznie cech jakościowych możliwych do opisania z wykorzystaniem dyferencjału semantycznego posłużono się transakcjami dotyczącymi praw do lokali mieszkalnych o praktycznie identycznych powierzchniach, położnych w zbliżonych konstrukcyjnie budynkach.

Ostatecznie wyodrębniono następujące zbiory: zbiór $\mathrm{O}_{\mathrm{B}}$ obejmujący 43 transakcje dotyczące spółdzielczych własnościowych praw do lokali mieszkalnych położonych na terenie Bydgoszczy, zawarte w okresie od lutego 2014 r. do października 2015 r., oraz zbiór $\mathrm{O}_{\mathrm{SZ}}$ obejmujący 55 transakcji dotyczących spółdzielczych własnościowych praw do lokali mieszkalnych położonych na terenie Szczecina, zawartych w okresie od stycznia 2010 r. do grudnia 2012 r. Dodatkowo badanie rozszerzono o zbiór $\mathrm{O}_{\mathrm{sw}}$ obejmujący 47 transakcji dotyczących lokali mieszkalnych jako przedmiotów odrębnej własności położonych na terenie Świecia, zawartych w okresie od stycznia 2012 r. do lipca 2016 r. Dane pozyskano $\mathrm{z}$ aktów notarialnych.

W przypadku zbioru $\mathrm{O}_{\mathrm{B}}$ zastosowano liniową korektę cen transakcyjnych związaną z zaobserwowanymi zmianami poziomu cen w czasie na poziomie $4 \%$ w stosunku rocznym. W przypadku zbiorów $\mathrm{O}_{\mathrm{Sz}}$ i $\mathrm{O}_{\mathrm{sw}}$ nie dokonano takiej korekty ze względu na brak zaobserwowanej istotnej zmiany cen w czasie. Dla opisanych zbiorów w odniesieniu do cen transakcyjnych przeprowadzono testy normalności. Na podstawie przeprowadzonych testów Shapiro-Wilka, Andersona-Darlinga oraz Kołmogorowa-Smirnowa nie znaleziono podstaw do odrzucenia hipotezy zerowej, natomiast w przypadku testu Kołmogorowa-Smirnowa dla cen ze zbioru $\mathrm{O}_{\mathrm{B}}$ oraz testu Shapiro-Wilka dla cen ze zbiorów $\mathrm{O}_{\mathrm{SZ}} \mathrm{i}_{\mathrm{SW}}$ zanotowano stosunkowo niskie wartości $p$ (tabela 1).

W ramach cech różnicujących analizowane zbiory w sensie jakościowym wyróżniono następujące cechy:

- lokalizacja $\left(X_{1}\right)$,

- stan techniczno-użytkowy budynku $\left(X_{2}\right)$,

- płożenie na kondygnacji $\left(X_{3}\right)$. 
Tabela 1. Zestawienie wyników testów normalności

\begin{tabular}{|c|c|c|}
\hline Test normalności & Wartość statystyki testowej & Wartość $p$ \\
\hline \multicolumn{3}{|c|}{ Zbiór $\mathrm{O}_{\mathrm{B}}$} \\
\hline Shapiro-Wilka & 0,96901 & 0,2922 \\
\hline Andersona-Darlinga & 0,42118 & 0,3097 \\
\hline Kołmogorowa-Smirnowa & 0,10931 & 0,2210 \\
\hline \multicolumn{3}{|c|}{ Zbiór $\mathrm{O}_{\mathrm{SZ}}$} \\
\hline Shapiro-Wilka & 0,97038 & 0,1915 \\
\hline Andersona-Darlinga & 0,36869 & 0,4166 \\
\hline Kołmogorowa-Smirnowa & 0,076985 & 0,5751 \\
\hline \multicolumn{3}{|c|}{ Zbiór $\mathrm{O}_{\mathrm{SW}}$} \\
\hline Shapiro-Wilka & 0,96311 & 0,1068 \\
\hline Andersona-Darlinga & 0,45041 & 0,2651 \\
\hline Kołmogorowa-Smirnowa & 0,071827 & 0,7225 \\
\hline
\end{tabular}

Źródło: obliczenia własne w programie R.

Dla wyspecyfikowanych zmiennych przyjęto skalę ocen (skala Osgooda) opisaną w tabeli 2.

Tabela 2. Skala ocen dla analizowanych zmiennych jakościowych

\begin{tabular}{|c|l|l|}
\hline Zmienna & \multicolumn{1}{|c|}{ Zbiór $\mathrm{O}_{\mathrm{B}}$} & \multicolumn{1}{|c|}{${\text { Zbiory } \mathrm{O}_{\mathrm{SZ}} \mathrm{i} \mathrm{O}_{\mathrm{SW}}}$} \\
\hline$X_{1}$ & 1. średnia, 2. dobra, 3. bardzo dobra & 1. gorsza, 2. lepsza \\
\hline$X_{2}$ & 1. średni (+), 2. dobry, 3. dobry (+) & 1. dobry, 2. dobry (+), 3. bardzo dobry \\
\hline$X_{3}$ & 1. średnie, 2. dobre, 3. bardzo dobre & 1. średnie, 2. dobre, 3. bardzo dobre \\
\hline
\end{tabular}

Źródło: obliczenia własne.

Każdą z nieruchomości w analizowanych zbiorach opisano trzema wyspecyfikowanymi zmiennymi, stosując przyjętą skalę ocen według schematu zamieszczonego w tabelach 3-5 (z uwagi na obszerność danych w tabelach zamieszczono dane tylko dla pierwszej i ostatniej nieruchomości w każdym zbiorze).

W kolejnym etapie badania oszacowano parametry równań regresji wielorakiej metodą najmniejszych kwadratów dla zmiennych opisanych na skali Osgooda oraz dla zmiennych sztucznych. W trakcie budowy modelu obejmującego wszystkie zmienne w stosunku do analizowanych zbiorów zaobserwowano nieistotność parametrów modelu dla cechy oznaczonej jako $X_{3}$ opisującej w ujęciu jakościowym położenie na określonej kondygnacji. Następnie pominięto tę zmienną i szacowano parametry modeli z dwiema zmiennymi objaśniającymi $X_{1}, \mathrm{X}_{2}$. 
Tabela 3. Opis stanów cech dla zbioru $\mathrm{O}_{\mathrm{B}}$ nieruchomości podobnych, kwantyfikacja według skali Osgooda i przekształcenie na zmienne sztuczne

\begin{tabular}{|c|c|c|c|c|c|c|c|c|c|c|}
\hline \multicolumn{2}{|c|}{ Lokale oceniane } & \multicolumn{3}{|c|}{$\begin{array}{c}\text { Ocena cech w skali } \\
\text { Osgooda }\end{array}$} & \multicolumn{6}{|c|}{ Ocena cech - zmienne sztuczne } \\
\hline Lp. & Oznaczenie & $X_{1}$ & $X_{2}$ & $X_{3}$ & $D_{11}$ & $D_{12}$ & $D_{21}$ & $D_{22}$ & $D_{31}$ & $D_{32}$ \\
\hline 1 & L1 & 1 & 1 & 1 & 0 & 0 & 0 & 0 & 0 & 0 \\
\hline$\ldots$ & $\ldots$ & & & & & $\ldots$ & & & & \\
\hline 43 & L43 & 2 & 2 & 1 & 1 & 0 & 1 & 0 & 0 & 0 \\
\hline
\end{tabular}

Źródło: obliczenia własne.

Tabela 4. Opis stanów cech dla zbioru $\mathrm{O}_{\mathrm{Sz}}$ nieruchomości podobnych, kwantyfikacja według skali Osgooda i przekształcenie na zmienne sztuczne

\begin{tabular}{|c|c|c|c|c|c|c|c|c|c|}
\hline \multicolumn{2}{|c|}{ Lokale oceniane } & \multicolumn{9}{|c|}{ Ocena cech w skali Osgooda } & \multicolumn{7}{|c|}{ Ocena cech - zmienne sztuczne } \\
\hline Lp. & Oznaczenie & $X 1$ & $X 2$ & $X 3$ & $D_{11}$ & $D_{21}$ & $D_{22}$ & $D_{31}$ & $D_{32}$ \\
\hline 1 & L1 & 2 & 1 & 1 & 1 & 0 & 0 & 0 & 0 \\
\hline$\ldots$ & $\ldots$ & \multicolumn{7}{|c|}{$\ldots$} \\
\hline 55 & L55 & 1 & 3 & 2 & 0 & 0 & 1 & 1 & 0 \\
\hline
\end{tabular}

Źródło: obliczenia własne.

Tabela 5. Opis stanów cech dla zbioru $\mathrm{O}_{\mathrm{SW}}$ nieruchomości podobnych, kwantyfikacja według skali Osgooda i przekształcenie na zmienne sztuczne

\begin{tabular}{|c|c|c|c|c|c|c|c|c|c|}
\hline \multicolumn{2}{|c|}{ Lokale oceniane } & \multicolumn{9}{|c|}{ Ocena cech w skali Osgooda } & \multicolumn{7}{c|}{ Ocena cech - zmienne sztuczne } \\
\hline Lp. & Oznaczenie & $X_{1}$ & $X_{2}$ & $X_{3}$ & $D_{11}$ & $D_{21}$ & $D_{22}$ & $D_{31}$ & $D_{32}$ \\
\hline 1 & L1 & 2 & 2 & 1 & 1 & 0 & 0 & 0 & 0 \\
\hline$\ldots$ & $\ldots$ & \multicolumn{7}{|c|}{$\ldots$} \\
\hline 47 & L47 & 1 & 1 & 1 & 0 & 0 & 0 & 0 & 0 \\
\hline
\end{tabular}

Źródło: obliczenia własne.

Dla zbioru $\mathrm{O}_{\mathrm{B}}$ i zmiennych opisanych za pomocą dyferencjału semantycznego:

$$
\begin{gathered}
\bar{R}^{2}=77,90, V=0,1157, \\
\hat{y}_{i}=2090,19+411,45 x_{1 i}+422,02 x_{2 i} .
\end{gathered}
$$

Dla zbioru $\mathrm{O}_{\mathrm{B}}$ i zmiennych opisanych za pomocą zmiennych sztucznych:

$$
\begin{gathered}
\bar{R}^{2}=77,50, V=0,1163, \\
\hat{y}_{i}=\underset{(112,25)}{2841,56}+\underset{(115,61)}{440,39} d_{1-1 i}+\underset{(153,18)}{839,31} d_{1-2 i}+\underset{(115,61)}{508,60 d_{2-1 i}}+\underset{(153,18)}{860,46} d_{2-2 i} .
\end{gathered}
$$


Dla zbioru $\mathrm{O}_{\mathrm{Sz}}$ i zmiennych opisanych za pomocą dyferencjału semantycznego:

$$
\begin{aligned}
& \bar{R}^{2}=74,30, V=0,0741, \\
& \hat{y}_{i}=\underset{(187,03)}{2468,99}+\underset{(73,95)}{345,04} x_{1 i}+\underset{(73,95)}{670,97} x_{2 i} .
\end{aligned}
$$

Dla zbioru $\mathrm{O}_{\mathrm{SZ}}$ i zmiennych opisanych za pomocą zmiennych sztucznych:

$$
\begin{gathered}
\bar{R}^{2}=74,60, V=0,0871, \\
\hat{y}_{i}=\underset{(92,51)}{3424,73}+\underset{(73,60)}{350,25 d_{1-1 i}}+\underset{(88,24)}{761,08 d_{2-1 i}}+\underset{(109,33)}{1366,07} d_{2-2 i} .
\end{gathered}
$$

Dla zbioru $\mathrm{O}_{\mathrm{Sw}}$ i zmiennych opisanych za pomocą dyferencjału semantycznego:

$$
\begin{aligned}
& \bar{R}^{2}=69,72, V=0,0990, \\
& \hat{y}_{i}=1464,51+526,36 x_{1 i}+373,24 x_{2 i} .
\end{aligned}
$$

\begin{tabular}{|c|c|c|c|c|c|c|}
\hline \multirow{2}{*}{ Wyszczególnienie } & \multicolumn{6}{|c|}{ Oznaczenie zmiennych } \\
\hline & \multicolumn{3}{|c|}{$X_{1}$} & \multicolumn{3}{|c|}{$X_{2}$} \\
\hline \multicolumn{7}{|c|}{ Model dla zbioru $\mathrm{O}_{\mathrm{B}}$} \\
\hline Stany cech według skali Osgooda & 1 & 2 & 3 & 1 & 2 & 3 \\
\hline $\begin{array}{l}\text { Wartości współczynników dla zmiennych } \\
\text { sztucznych }\end{array}$ & 0 & 440,39 & 839,31 & 0 & 508,6 & 860,46 \\
\hline $\begin{array}{l}\text { Proporcja w stosunku do wartości maksy- } \\
\text { malnej }\end{array}$ & 0 & 0,5247 & 1 & 0 & 0,5911 & 1 \\
\hline \multicolumn{7}{|c|}{ Model dla zbioru $\mathrm{O}_{\mathrm{SZ}}$} \\
\hline Stany cech według skali Osgooda & 1 & - & 2 & 1 & 2 & 3 \\
\hline $\begin{array}{l}\text { Wartości współczynników dla zmiennych } \\
\text { sztucznych }\end{array}$ & 0 & - & 350,25 & 0 & 761,08 & 1366,1 \\
\hline $\begin{array}{l}\text { Proporcja w stosunku do wartości maksy- } \\
\text { malnej }\end{array}$ & 0 & - & 1 & 0 & 0,5571 & 1 \\
\hline \multicolumn{7}{|c|}{ Model dla zbioru $\mathrm{O}_{\mathrm{SW}}$} \\
\hline Stany cech według skali Osgooda & 1 & - & 2 & 1 & 2 & 3 \\
\hline $\begin{array}{l}\text { Wartości współczynników dla zmiennych } \\
\text { sztucznych }\end{array}$ & 0 & - & 527,38 & 0 & 364,79 & 751,39 \\
\hline $\begin{array}{l}\text { Proporcja w stosunku do wartości maksy- } \\
\text { malnej }\end{array}$ & 0 & - & 1 & 0 & 0,4855 & 1 \\
\hline
\end{tabular}

Dla zbioru $\mathrm{O}_{\mathrm{Sw}}$ i zmiennych opisanych za pomocą zmiennych sztucznych:

$$
\begin{gathered}
\bar{R}^{2}=69,04, V=0,0990, \\
\hat{y}_{i}=\underset{(75,95)}{2368,97}+\underset{(58,87)}{527,38 d_{1-1 i}}+\underset{(73,71)}{364,79 d_{2-1 i}}+\underset{(112,23)}{751,39 d_{2-2 i}} .
\end{gathered}
$$

Tabela 6. Porównanie wyników estymacji współczynników dla opisu stanów cech, kwantyfikacja według skali Osgooda i przekształcenie na zmienne sztuczne

Źródło: obliczenia własne. 
Na podstawie modeli uzyskanych z wykorzystaniem zmiennych sztucznych określono proporcje pomiędzy wpływem na zmienną objaśnianą poszczególnych stanów cech opisanych za pomocą zmiennych sztucznych a odpowiadających określonym ocenom cech dokonanym z uwzględnieniem skali Osgooda. Zestawienia wyników dokonano w tabeli 6.

\section{Wnioski}

Uzyskane wyniki dla analizowanych trzech zbiorów (podobnie jak w przypadku wstępnych wyników uzyskanych dla dwóch zbiorów [Foryś i Gaca 2016b]) nie dają podstaw do odrzucenia postawionej hipotezy odnoszącej się do możliwości traktowania zmiennych jakościowych skwantyfikowanych z wykorzystaniem dyferencjału semantycznego jak zmiennych co najmniej interwałowych. Mimo iż obliczone interwały dla poszczególnych stanów cech wyrażające się poprzez wartości współczynników dla zmiennych sztucznych nie są idealnie proporcjonalne, zaobserwowane odchylenia są stosunkowo niewielkie. Uzyskane w trakcie badania wyniki potwierdzają wnioski płynące $\mathrm{z}$ analizy innych zbiorów opartej na porównaniu wyników korelacji [Foryśs i Gaca 2016a, 2016b].

Należy zwrócić uwagę, że proporcjonalne odwzorowanie wpływu zmiennych jakościowych wyrażonych za pomocą skali Osgooda miało miejsce w stosunku do trzech zbiorów nieruchomości podobnych przy zachowaniu bardzo dużego podobieństwa w zakresie podstawowych cech wpływających na kształtowanie cen (powierzchnia, funkcjonalność, lokalizacja ogólna, rodzaj budynku itp.). Biorąc pod uwagę wyniki uzyskane w opisanej analizie, można przyjąć, że dla zbiorów nieruchomości o znacznym podobieństwie fizycznym, różniących się w obszarze cech jakościowych możliwe jest uwzględnienie w modelach wyceny bezpośrednio stanów cech jakościowych skwantyfikowanych za pomocą dyferencjału semantycznego. Kwestia zachowania się zmiennych jakościowych skwantyfikowanych za pomocą dyferencjału semantycznego dla zbiorów nieruchomości o większym zróżnicowaniu cech wymaga dalszych pogłębionych analiz.

Badana możliwość wykorzystania dyferencjału semantycznego do pomiaru cech jakościowych w wycenie nieruchomości ma zdaniem autorów niniejszego artykułu bardzo duże znaczenie praktyczne w procesie szacowania wartości rynkowej nieruchomości. Uwzględnienie skali Osgooda poprzez zastosowanie wystandaryzowanego narzędzia pomiarowego wpływa na zmniejszenie subiektywności ocen dokonywanych przez poszczególnych rzeczoznawców, a tym samym może wpływać na zwiększenie poprawności wycen. Ponadto zastosowanie pomiaru zmiennych jakościowych z wykorzystaniem dyferencjału semantycznego przy uwzględnieniu co najmniej interwałowego charakteru takiego 
pomiaru ma istotne znaczenie aplikacyjne pozwalające na uwzględnianie tego typu danych w modelach regresji wielorakiej bez transformacji na zmienne instrumentalne. Kolejne badania prowadzone będą na rynkach innych miast oraz dla innych rodzajów nieruchomości, a ich wyniki weryfikowane będą w praktyce rzeczoznawstwa majątkowego.

\section{Literatura}

Bełej M., Źróbek S. [2000], Podejście porównawcze w szacowaniu nieruchomości, Educaterra, Olsztyn.

Bennett A., Elman C. [2006]. Qualitative Research: Recent Developments in Case Study Methods, „Annual Review of Political Science”, vol. 9, nr 1, https://doi.org/10.1146/ annurev.polisci.8.082103.104918.

Foryś I. [2011], Wykorzystanie metod taksonomicznych do wyboru obiektów podobnych w procesie wyceny lokali mieszkalnych, ,Studia i Materiały Towarzystwa Naukowego Nieruchomości”, vol. 18, nr 1.

Foryś I., Gaca R. [2016a], Aplikacja skal Likerta i Osgooda do kwantyfikacji stanów cech jakościowych nieruchomości, „Folia Oeconomica Stetinensia”, vol. 16, nr 2.

Foryś I., Gaca R. [2016b], Theoretical and Practical Aspects of Qualitative Variable Descriptions of Residential Property Valuation Multiple Regression Models [w:] The 10th Professor Aleksander Zelias International Conference on Modelling and Forecasting of Socio-Economic Phenomena, red. M. Papież, S. Śmiech, Foundation of the Cracow University of Economics, Cracow.

Green S.B. [1991], How Many Subject Does It Take to Do A Regression Analysis: A Model Selection Perspective, „Multivariate Behavioral Research”, vol. 26, nr 3, https://doi. org/10.1207/s15327906mbr2603_7.

Hardy M.A. [1993], Regression with Dummy Variables, SAGE University Papers, Quantitative Applications in the Social Sciences, nr 93, SAGE Publications, Newbury Park.

Hozer J. [2001], Regresja wieloraka a wycena nieruchomości, ,Rzeczoznawca Majątkowy", nr 2.

Johnson J.W. [2010], A Heuristics Method for Estimating the Relative Weight of Predictor Variables in Multiple Regression, „Multivariate Behavioral Research”, vol. 35, nr 1, https://doi.org/10.1207/s15327906mbr3501_1.

Knapp T.R. [1990], Treating Ordinal Scales as Interval Scales: An Attempt To Resolve the Controversy, „Nursing Research”, vol. 39, nr 2, https://doi.org/10.1097/00006199199003000-00019.

Osgood C.E., Suci G., Tannenbaum P. [1957], The Measurement of Meaning, University of Illinois Press, Urbana.

Preacher K.J., Zhang G., Kim Ch., Mels G. [2013], Choosing the Optimal Number of Factors in Exploratory Factor Analysis: A Model Selection Perspective, „Multivariate Behavioral Research", vol. 48, nr 1, https://doi.org/10.1080/00273171.2012.710386.

Social Entrepreneurship and Research Methods [2014], red. D.J. Ketchen, D.D. Bergh, Research Methodology in Strategy and Management, vol. 9, Emerald Group Publishing Limited, United Kingdom. 
Stevens S.S. [1946], On the Theory of Scales of Measurement, „Science”, vol. 103, nr 2684, https://doi.org/10.1126/science.103.2684.677.

Walesiak M. [1996], Dopuszczalne działania na liczbach $w$ badaniach marketingowych z punktu widzenia skal pomiarowych, „Prace Naukowe Akademii Ekonomicznej we Wrocławiu", nr 718.

Walesiak M. [2014], Wzmacnianie skali pomiaru dla danych porzqdkowych $w$ statystycznej analizie wielowymiarowej, „Prace Naukowe Uniwersytetu Ekonomicznego we Wrocławiu", nr 327.

Walesiak M., Dudek A. [2007], Symulacyjna optymalizacja wyboru procedury klasyfikacyjnej dla danego typu danych - charakterystyka problemu, „Zeszyty Naukowe Uniwersytetu Szczecińskiego. Prace Katedry Ekonometrii i Statystyki”, nr 17.

Wiśniewski J.W. [1986], Korelacja i regresja w badaniach zjawisk jakościowych na tle teorii pomiaru, „Przegląd Statystyczny”, nr 3.

\section{Theoretical and Practical Aspects of Qualitative Variable Descriptions of Residential Property Valuation Multiple Regression Models}

(Abstract)

The increasing number of transactions and areas of economic activity requiring the value of real estate to be determined have prompted attempts to implement multiple regression models to increase as well. However, the imperfections of regression modeling, and property as real objects described in the models, lead to contradictory and unjustified conclusions. One of the reasons for the functional imperfections of regression models is the method employed for inputting qualitative variables. Unfortunately, these variables are most commonly used in the decryption of property characteristics.

According to the principles defining possible operations on numbers depending on the type of measurement scale used (nominal and ordinal), the qualitative variables can be introduced into regression models as dummy variables. In this article, we propose an alternative method for implementing qualitative variables (describing the real estate markets) in multiple regression models, by applying Osgood scale to measure them.

This paper presents not only a theoretical basis of the proposed model but also the results of empirical data on the classical method of using qualitative variables. The theoretical considerations are supported by an empirical study on the residential housing market in Szczecin, Bydgoszcz and Świecie (zachodniopomorskie voivodeship).

Keywords: residential property valuation, qualitative variables, Osgood scale, semantic scale, multiple regression. 